\title{
Struktur dan Proses Komunikasi dalam Poster Pemanasan Global Victor Van Gasbeek
}

\author{
Deni Albar \\ Program Studi Desain Komunikasi Visual, Universitas Komputer Indonesia
}

\begin{abstract}
Abstrak. Media merupakan bagian dari kehidupan sehari-hari umat manusia. Interaksi yang terjadi antara manusia dengan media hampir terjadi setiap hari. Interaksi antara manusia sebagai pengguna (user) atau penyimak (viewer) dari suatu objek media dapat dilihat sebagai suatu bentuk komunikasi. Poster mengenai pemanasan global yang didesain Victor van Gaasbeek (2009) tentunya dapat memiliki kekuatan yang menjadi sumber ide dan opini bagi yang melihatnya. Dengan topik pemanasan global yang hadir pada poster ini, maka menarik apabila dapat diuraikan elemen komunikasi, multimodality beserta relasi antar modes dalam poster tersebut.
\end{abstract}

Dalam penelitian ini menggunakan pendekatan multimodality sebagai salah satu cara menelaah objek. Multimodality dari media poster pemanasan global karya Victor van Gaasbeek (2009) memiliki modes yang menarik untuk ditelaah. Gabungan dari modes ini menjadi suatu multimodal text yang dapat dimaknai berdasarkan pemahaman audiens. Dalam poster ini, mode tampil secara visual yang memiliki makna baik secara konotasi maupun denotasi. Dari penelitian menggunakan teori multimodality, maka dapat disimpulkan interaksi antara manusia sebagai user atau viewer dengan medianya merupakan suatu bentuk komunikasi. Komunikasi ini dapat berjalan baik apabila pengirim pesan mampu memberikan pesan melalui medium yang dipilihnya serta pesan dapat dipahami oleh audiens. Pesan mengenai pemanasan global dalam poster dapat dipahami jika audiens memahami referent yang digunakan desainernya.

Kata kunci: komunikasi, multimodality, poster, Victor van Gaasbeek

\section{PENDAHULUAN}

Media merupakan bagian dari kehidupan sehari-hari umat manusia. Interaksi yang terjadi antara manusia dengan media hampir terjadi setiap hari. Interaksi antara manusia sebagai pengguna (user) atau penyimak (viewer) dari suatu objek media dapat dilihat sebagai suatu bentuk komunikasi. Interaksi yang terjadi antara desainer, media dan audiens, dianggap memiliki suatu kekuatan seperti apa yang diungkapkan oleh Burton (2008, p.2) bahwa "Kekuatan utama media terletak pada fakta bahwa media dapat membentuk apa yang kita ketahui tentang dunia dan dapat menjadi sumber utama pelbagai ide dan opini”.Berikut merupakan sebuah gambar dari poster kampanye sosial pemanasan global sebagai produk desain 
yang menjadi objek kajian. Gambar poster pemanasan global ini merupakan karya desain dari Victor van Gaasbeek (2009).

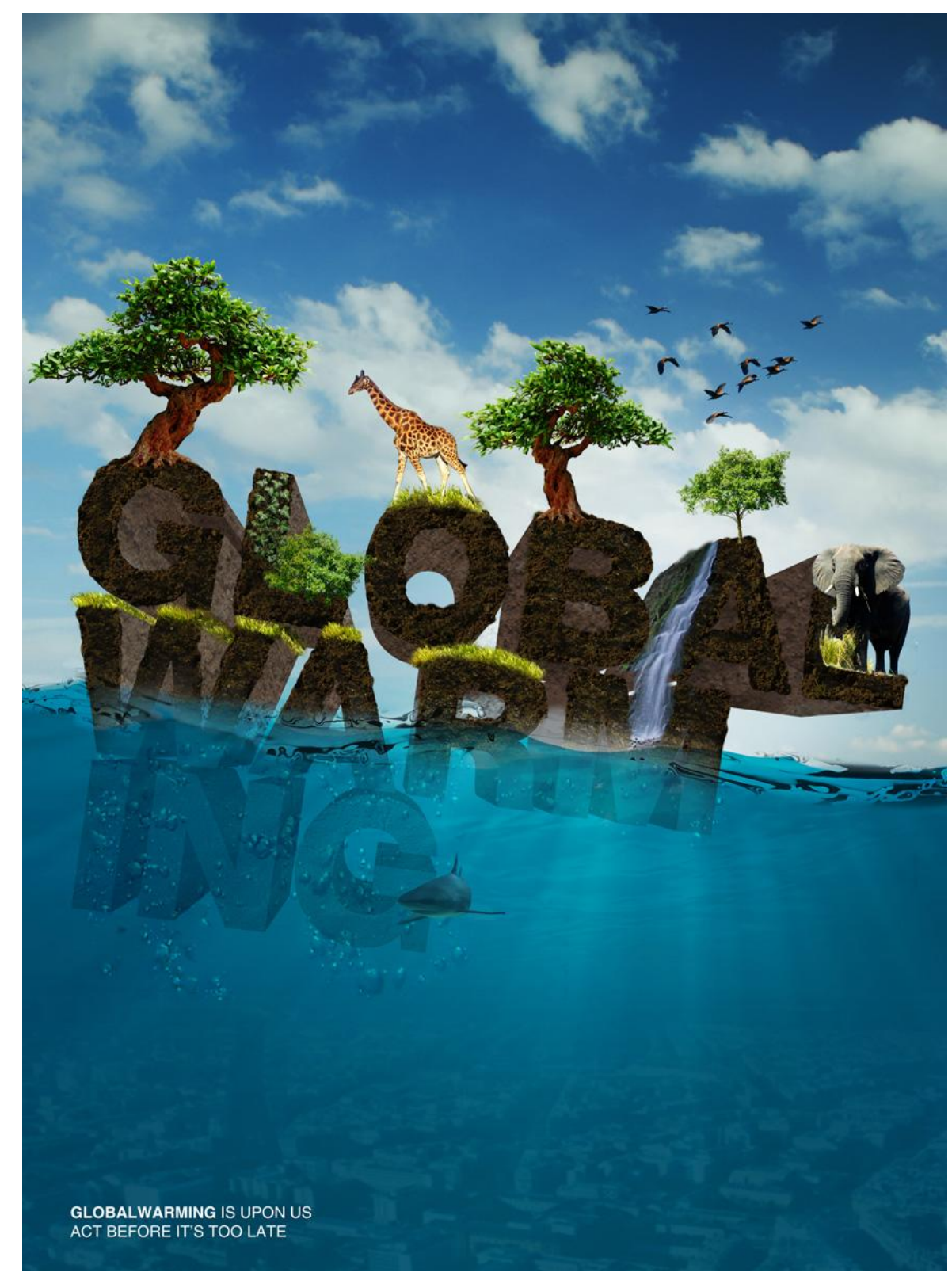

Gambar 1.1. Poster Global Warming Environmental

Sumber: http://www.victorvangaasbeek.com/work/global_warming.htm (diambil pada12/10/2010)

Poster pemanasan global ini pernah digunakan dalam "The East Asian Seas Congress 2009" yang diselenggarakan dan merupakan kerja sama dari Environmental Management for the Seas of East Asia (PEMSEA) dan DENR 
serta didukung Global Environment Facility, United Nations Development Programme, United Nations Office for Project Services and Coastal Management Center. (Victor van Gaasbeek. 2009).Poster mengenai pemanasan global yang didesain Victor van Gaasbeek (2009) tentunya dapat memiliki kekuatan yang menjadi sumber ide dan opini bagi yang melihatnya. Dengan topik pemanasan global yang hadir pada poster ini, maka menarik apabila dapat diuraikan elemen komunikasi, multimodality beserta relasi antar modes dalam poster tersebut.

\section{METODE \& PEMBAHASAN}

Metode multimodality merupakan suatu cara yang dapat memberikan penjelasan terhadap suatu karya desain, sangat mungkin digunakan untuk menelaah poster glabal warming karya Victor van Gaasbeek.

\section{A. Elemen Komunikasi}

Elemen komunikasi yang terdapat dalam interaksi antara manusia dengan poster ini diantaranya adalah pengirim pesan (sender), penerima pesan (receiver), pesan itu sendiri (message), referent, medium, dan makna (meaning). Desainer merancang sebuah objek desain yang didalamnya terkandung pesan dan referent yang kemudian diterima audiens dengan pemahaman yang audiens miliki. Pemahaman audiens ini dipengaruhi berbagai hal seperti sosial, budaya, pendidikan serta hal-hal lainnya. Berdasarkan pemahamannya, audiens membaca teks sebagai sebuah objek desain yang didalamnya terdapat tanda. Apabila dilihat dari tipe interaksi, menurut Holmes (n.d.), maka poster termasuk mediated quasi-interaction, dimana media bersifat monological atau tidak terjadi dialog antara desainer dengan audiens. Berikut penjabaran dari elemen komunikasi dari poster bertema pemanasan global ini;

- Pengirim pesan

Ada tiga kemungkinan yang menjadi pengirim pesan dalam poster pemanasan global ini. Bisa desainernya, bisa klien desainernya, atau keduanya. Klien mungkin saja mengatur secara implisit dan eksplisit tampilan media, sehingga desainer hanya berperan sebagai visualizer. 
- Penerima pesan

Penerima pesan dari poster ini adalah audiens yang melihat atau menyimak dari tampilan poster. "Orang-orang yang membuat materi media pada saat yang sama merupakan bagian dari audiens bagi materi mereka sendiri” (Burton, 2008, p.209).

- $\quad$ Pesan, referent dan makna

Elemen pesan, referent dan makna dapat diartikan bermacam-macam tergantung dari pengetahuan atau pemahaman audiensnya. Poster dalam bentuk metafora yang mungkin tidak semua kalangan masyarakat mampu membaca denotasi yang disampaikan. Pesan ini dapat dibaca dari berbagai referent yang tampil dalam poster tersebut, berupa modes beserta relasinya yang memiliki makna.

- Medium

Seperti yang diungkapkan Hartley (2000) dikutip dari Trisnawati (2010) mengenai medium, "Any material through which something else may be transmited." Pada saat penulis mengunduh dari sumber diinternet, medium berupa digital image, namun setelah di cetak maka medium untuk menyampaikan pesan berubah menjadi poster kertas.

\section{B. Multimodality}

Multimodality dari media poster pemanasan global karya Victor van Gaasbeek (2009) memiliki modes yang menarik untuk ditelaah. Gabungan dari modes ini menjadi suatu multimodal text yang dapat dimaknai berdasarkan pemahaman audiens. Modes yang dimiliki poster ini diantarannya;

- Mode warna. Warna secara keseluruhan dalam poster menampilkan warna cerah, mode dari warna ini dapat memiliki pesan cuaca yang cerah atau panas yang biasa terjadi di kawasan dengan kondisi iklim tertentu. 
- Mode gambar hewan

- Mode gambar gajah. Visualisasi gajah yang tampil dalam poster tersebut, berupa gajah dari benua Afrika, hal tersebut dapat dilihat dari jenis telinga gajah yang melebar. Dalam situs National Geographic dikatakan "African elephants are the largest land animals on Earth. They are slightly larger than their Asian cousins and can be identified by their larger ears that look somewhat like the continent of Africa." (National Geographic. 2010).

○ Mode gambar jerapah. Hewan dengan habitat asli dari Afrika. "A single species with nine recognized subspecies, the giraffe is an herbivore native to Africa that lives in the savanna areas south of the Sahara” (Cocke. 2010).

- Mode gambar hiu. Hiu merupakan hewan laut yang dianggap berbahaya bagi sebagian besar masyarakat. Seringkali dianggap sebagai ancaman dilaut.

- Mode gambar burung. Tampil sebagai hewan yang mampu untuk tidak berpijak ditanah dalam waktu tertentu.

- Mode gambar tumbuhan. Yang paling menonjol yaitu dua objek pohon khas Afrika yaitu Acacia tortilis atau Umbrella thorn. Pohon khas dengan habitat kawasan Afrika. "The Umbrella Thorn is one of the most widely distributed Acacia's. This tree can be found in Mozambique, Botswana, Swaziland, Tranvaal, Orange Free State and the Cape” (Kruger Park. 2010).

- Mode gambar air terjun. Mode gambar air terjun berada diposisi tinggi huruf A.

- Mode gambar kota terendam. Tampil seperti suatu peradaban yang musnah.

- Mode gambar latar langit. Tampil dengan cerah menggambarkan kondisi cuaca.

- Mode gambar air. Tampil dengan komposisi yang cukup besar hampir menyerupai mode langit dan lebih banyak dibanding daratan. 
- Mode gelembung air. Menampilkan kesan objek yang tenggelam dan mengikis.

- Mode Tulisan. Terbagi menjadi dua, headlinetext "Global Warming" dan copytext "Global Warming is upon us, act before it's too late".

- Mode tekstur tanah. Tampil pada tulisan headline membentuk kesan daratan.

- Mode layout dan framing. Membingkai tata cara kita melihat dan menyikapi apa yang tampil. Mode framing membingkai pemahaman audiens dari satu mode ke mode yang lainnya sehingga membentuk suatu pemahaman.

Media sebagai objek desain hadir dengan modes. Modes menjadi sebuah modal dalam produk desain dan idealnya mampu merepresentasikan pesan yang akan disampaikan. Pesan yang hadir dalam media kemudian dimaknai dan secara sosial mengkontruksi sebuah pemahaman yakni suatu discourse. Poster global warming ini merupakan suatu bentuk discourse, secara sosial terkontruksi menjadi pengetahuan dan pemahaman oleh audiensnya. Kontruksi sosial terjadi pada saat modes saling berelasi, dan menimbulkan pemahaman dibenak khalayak, misal 'siapa yang akan terkena permasalahan pemanasan global?', 'dimana pemanasan global terjadi?', 'kapan dampak pemanasan global mungkin terjadi?', kontruksi-kontruksi sosial tersebut akan terbentuk dalam benak audiens melalui media. Discourse desain poster ini diproduksi dan didistribusikan sehingga membentuk suatu kepercayaan dalam benak masyarakat dan membentuk multimodal communication,medianya sendiri merupakan multimodal text.

\section{Relasi antar Modes}

Hubungan antara mode yang satu dengan mode yang lain tentunya membentuk suatu pemahaman tertentu tergantung pemahaman audiensnya. Dalam poster ini, mode tampil secara visual yang memiliki makna baik secara konotasi maupun denotasi. Relasi antara mode seperti gajah, jerapah 
dan mode tumbuhan seperti mode pohon umbrella thorn, menganalogikan kawasan benua Afrika.

Mengapa benua Afrika?, bukan hanya persepsi masyarakat, namun berupa fakta mengenai iklim di Afrika bahwa "Temperatures remain high throughout the year, averaging more than $27^{\circ} \mathrm{C}\left(81^{\circ} \mathrm{F}\right)$ annually, and rarely falling below $21^{\circ} \mathrm{C}\left(70^{\circ} \mathrm{F}\right)$ " (Newman, Mehretu, Shilington \& Rock. 2008). Afrika merupakan benua dataran tinggi dengan pegunungan-pegunungan tinggi seperti Kalimanjaro dan Victoria dengan air terjun dataran tinggi yang mungkin diwakili dengan mode air terjun pada huruf ' $\mathrm{A}$ ' dalam poster. Benua Afrika juga ditampilkan sebagai benua yang mungkin terakhir tenggelam. Sehingga terdapat sebuah makna bahwa tempat seperti Afrika yang memiliki dataran tinggi sekalipun terancam bahaya pemanasan global, maka dapat dipastikan daratan lainnya pun terancam hal yang sama dan dapat dipastikan kondisinya lebih panas dari kondisi saat ini.

Relasi antara mode hewan burung dengan modes lainnya menimbulkan makna denotasi yaitu mahluk yang memiliki kelebihan seperti burung dan mampu terbang saja membutuhkan pijakan, sehingga dengan kata lain dapat diasumsikan semua mahluk terancam termasuk manusia yang merasa memiliki 'kelebihan'. Relasi antara mode air, mode hiu dengan mode tulisan "Global Warming" bertekstur tanah yang juga sebuah mode, menganalogikan ancaman pemanasan global, dimana air meluap mengikis daratan. Mode hiu muncul sebagai simbol ancaman / bahaya yang dihadapi sekaligus menegaskan mode air.

Mode tulisan "Global Warming" yang cenderung miring pada peletakannya juga menganalogikan ketidakseimbangan alam daratan yang terancam. Hubungan antara modes copytext "Global Warming is upon us, act before it's too late" mempertegas waktu dekat kemungkinan terjadinya dampak pemanasan global ini, mode kota tenggelam yang menganalogikan hilangnya peradaban serta berbagai visualisasi modes lainnya, membingkai pikiran 
audiens mengenai bahaya yang dihadapi dan membentuk suatu wacana mengenai pemanasan global.

\section{KESIMPULAN}

Dari analisis diatas, maka dapat disimpulkan interaksi antara manusia sebagai user atau viewer dengan medianya merupakan suatu bentuk komunikasi. Komunikasi ini dapat berjalan baik apabila pengirim pesan mampu memberikan pesan melalui medium yang dipilihnya serta pesan dapat dipahami oleh audiens. Pesan mengenai pemanasan global dalam poster dapat dipahami jika audiens memahami referent yang digunakan desainernya. Benua Afrika yang dijadikan referent dalam poster menggunakan modes yang pada umumnya telah dikenal masyarakat luas, misal modes hewan-hewan dan tumbuhan khas Afrika, sehingga kesalahpahaman referent dapat diminimalisir. Penggunaan modes yang tepat merupakan kunci kesuksesan dalam penyampaian pesan.

Salah paham komunikasi sangat mungkin terjadi apabila pemahaman atau referent dari pengirim pesan dengan penerima pesan berbeda, disebabkan oleh perbedaan budaya, sosial, pendidikan dan hal lainnya yang memungkinkan referent tidak sesuai antara pengirim pesan dan penerima pesan. Proses komunikasi ini dapat berjalan baik apabila elemen-elemen komunikasi yang ada didalamnya berada pada tataran pemahaman yang sama atau tidak terlalu jauh berbeda. Tatkala pesan poster diproduksi dan didistribusi, dipahami dan menjadi suatu pengetahuan yang kemudian secara sosial membentuk pemahaman, maka discourseglobal warming hadir dan terbentuk multimodal communication dari poster global warming tersebut.

\section{DAFTAR PUSTAKA}

Burton, G. (2008). Yang tersembunyi di balik media: Pengantar kepada kajian media. Yogyakarta, Indonesia: Jalasutra.

Cocke, A. (2009). Giraffe Description. Dikutip dari http://www.ehow.com/about_5437585_giraffe-description.html (12/10/2010). 
Gaasbeek, V. V. (2010). Global warming poster. Dikutip dari http://www.victorvangaasbeek.com/work/global_warming.htm (12/10/2010).

Holmes, D. (n.d.). The Fallacies and Fortunes of 'Interactivity' inCommunication Theory. Dikutip dari http://citeseerx.ist.psu.edu/viewdoc/download;jsessionid= 9BED8098D46911C2E7B7EDA3A907D84F?doi=10.1.1.107.823\&rep=rep1 \&type $=$ pdf

Kruger Park. (2010). Umbrella Thorn. Dikutip dari http://www.krugerpark.co.za/africa_umbrella_thorn.html (12/10/2010).

National Geographic. (2010). African Elephant. Dikutip dari http://animals.nationalgeographic.com/animals/mammals/africanelephant.html (12/10/2010).

Newman, J., Mehretu, A., Shilington, K., Stock, R. (2008). Africa. Microsoft ${ }^{\circledR}$ Encarta® 2009 [DVD]. Redmond, WA: Microsoft Corporation.

Trisnawati, Suranti. (2010). Understanding of communication with media [PowerPoint slides]. Bandung, Indonesia: Institut Teknologi Bandung. 